\title{
Qualidade fisiológica de sementes de crambe tratadas com zinco e molibdênio
}

Hugo Tiago Ribeiro Amaro, Andréia Márcia Santos de Souza David, Miquéias de Oliveira Assis, Josiane Cantuária Figueiredo, Lucas Vinícius de Souza Cangussú, Marina Borges de Oliveira Silva

Universidade Estadual de Montes Claros - UNIMONTES, Montes Claros, MG. E-mail: josycantuaria@yahoo.com.br

\section{Resumo}

A cultura do crambe vem ganhando importância no Brasil devido ao estímulo à produção e uso de biodiesel. E a aplicação de micronutrientes via tratamento de sementes visando aumentar a produtividade tem apresentado resultados positivos na agricultura. No entanto, pouco se sabe sobre o real efeito desses produtos na qualidade fisiológica de sementes de crambe. Desta forma, o objetivo do trabalho foi avaliar a qualidade fisiológica de sementes de Crambe abyssinica Hochst tratadas com fertilizante líquido a base de zinco e molibdênio. $O$ experimento foi conduzido no Laboratório de Análise de Sementes da Unimontes. $O$ delineamento experimental utilizado foi inteiramente casualizado, com quatro repetições. Os tratamentos testados constituíram de cinco doses de fertilizante comercial composto por zinco (35\%) e molibdênio (3,5\%), aplicados via semente nas concentrações de $0 ; 3,3 ; 6,7 ; 10$ e $13 \mathrm{~mL}$ do fertilizante para $0,5 \mathrm{Kg}^{-1}$ de sementes. A qualidade fisiológica das sementes foi avaliada por meio dos seguintes testes: germinação, primeira contagem de germinação, emergência e comprimento de plântulas. Com o aumento das doses do fertilizante comercial composto por zinco e molibdênio, houve redução na germinação e vigor das sementes de crambe. A qualidade fisiológica das sementes de crambe é influenciada negativamente por doses crescentes de zinco e molibdênio.

Palavras-chave: Crambe abyssinica Hochst; micronutrientes; vigor.

\section{Physiological quality seeds crambe treated with zinc and molybdenum}

\begin{abstract}
The crambe culture has been gaining importance in Brazil due to the stimulus to the production and use of biodiesel. And the application of micronutrients via seed treatment has shown positive results in agriculture. However, little is known about the actual effect of these products on the physiological quality of crambe seeds. Thus, the objective of this work was to evaluate the physiological quality of Crambe abyssinica Hochst seeds treated with liquid fertilizer based on zinc and molybdenum. The experiment was conducted at the Unimontes Seed Analysis Laboratory. The experimental design was completely randomized, with four replications. The treatments tested consisted of five doses of commercial fertilizer composed of zinc (35\%) and molybdenum (3.5\%), applied via seed at concentrations of $0 ; 3.3 ; 6.7 ; 10$ and $13 \mathrm{~mL}$ of the fertilizer to $0.5 \mathrm{~kg}^{-1}$ of seeds. The physiological quality of the seeds was evaluated by means of the following tests: germination, first germination count, emergence and seedling length. With increasing doses of commercial fertilizer composed of zinc and molybdenum, there was a reduction in germination and vigor of crambe seeds. The physiological quality of crambe seeds is negatively influenced by increasing doses of zinc and molybdenum.
\end{abstract}

Keywords : Crambe abyssinica Hochst; micronutrients; vigor.

\section{Introdução}

O crambe (Crambe abyssinica Hochst) é uma espécie pertencente à família das crucíferas, originária da região do Mediterrâneo, e apresenta boa adaptação à diferentes condições climáticas (SOUZA et al., 2009). É uma oleaginosa 
ainda pouco estudada, que desponta com grande potencial para a produção de biodiesel devido ao considerável teor de óleo (36 a 38\%) presente em suas sementes (PITOL et al.,2010).

É crescente a demanda de sementes de alta qualidade com o intuito de assegurar populações adequadas de plantas em uma ampla faixa de condições ambientais visando uma agricultura mais produtiva (BARBOSA et al., 2012). E objetivando melhorar esse potencial produtivo tem-se incorporado aditivos nas sementes a base de micronutrientes.

A aplicação de aditivos á base de micronutrientes nas sementes é uma prática de adubação fácil, eficaz e de baixo custo para aplicação a qual garante maior uniformidade e distribuição de plantas (LUCHESE et al., 2004). Dentre os micronutrientes utilizados, tem-se o zinco e o molibdênio, os quais possuem importância específica na qualidade de sementes.

$O$ zinco é um micronutriente constituinte de enzimas, tais como; anidrase carbônica, desidrogenase alcoólica, superóxido dismutase (CuZnSOD) e aldolase. Bem como da sintetase do triptofano a qual é responsável pela produção de ácido indolacético (AIA) nos vegetais, que é fundamental tanto para o crescimento apical como para a expansão celular (EPSTEIN; BLOOM, 2004). A absorção do zinco aplicado nas sementes ocorre quase integralmente, aumentando a reserva da semente.

O molibdênio (Mo) é cofator da enzima oxidase do aldeído, que catalisa a etapa final da biossíntese dos fitohormônios ácido indoliacético (AIA) e ácido abscísico (ABA) (MENDEL; SCHWBARZ, 1999), fazendo com que as sementes com alto conteúdo de Mo também apresentem, níveis elevados de $A B A$, que controla processos fisiológicos essenciais na planta como germinação e desenvolvimento (MERLOT; GIRANDAT, 1997).

Assim, trabalhos que utilizam micronutrientes no tratamento de sementes são importantes, uma vez que as respostas que se têm até o momento são obtidas de forma isolada.

Face às considerações, objetivou-se com o presente trabalho avaliar a qualidade fisiológica de sementes de Crambe abyssinica Hochst tratadas com fertilizante líquido composto de zinco e molibdênio.

\section{Material e Métodos}

O experimento foi conduzido no Laboratório de Análise de Sementes, do Departamento de Ciências Agrárias, da Universidade Estadual de Montes Claros (UNIMONTES), Campus de Janaúba, Norte de Minas Gerais. Foram utilizadas sementes de crambe, cultivar FMS Brilhante, armazenadas sob condições controladas de temperaturas e umidade relativa $(16 \pm 2$ o C e $65 \pm 5 \%$ de UR), provenientes da Cooperativa Agropecuária Pioneira (COOAPI) localizada na região da Chapada Gaúcha, MG.

O delineamento experimental utilizado foi o inteiramente casualizado, com quatro repetições de 50 sementes por tratamento. Os tratamentos consistiram em cinco doses de fertilizante comercial Broadacre ${ }^{\circledR}$ composto por zinco (35\%) e molibdênio (3,5\%), diluído em água destilada e aplicados diretamente nas sementes nas quantidades de 0 (controle); 3,3; 6,7; 10 e 13 $\mathrm{mL}$ para $0,5 \mathrm{Kg}^{-1}$ de sementes.

Os micronutrientes foram aplicados diretamente nas sementes com auxílio de uma pipeta graduada, e em seguida acondicionadas em saco de polietileno com capacidade de $2,0 \mathrm{~kg}$. Após aplicação do fertilizante sobre as sementes, o conjunto foi agitado manualmente durante cinco minutos, afim de possibilitar a distribuição homogênea do produto. Para a caracterização da qualidade fisiológica das sementes foram realizados os testes e/ou determinações descritos a seguir:

Teor de água: Antes da aplicação dos tratamentos, o teor de água foi determinado pelo método da estufa a $105{ }^{\circ} \mathrm{C}$ por 24 horas, utilizando-se duas subamostras de $2 \mathrm{~g}$ de sementes (BRASIL, 2009).

Teste de germinação: Utilizaram-se caixas plásticas tipo gerbox, onde as sementes foram distribuídas sobre uma folha de papel mataborrão, previamente umedecidas com água destilada em volume equivalente a 2,5 vezes o peso do papel seco. Utilizou-se 4 repetições de 50 sementes por tratamento, e as caixas contendo as sementes foram colocadas em germinador previamente regulado à temperatura constante de 25 ㅇ. . As avaliações foram realizadas aos quatro e sete dias após a semeadura, sendo os resultados expressos em porcentagem de plântulas normais, conforme recomendação da RAS - Regras para Análise de Sementes (BRASIL, 2009). 
Primeira contagem de germinação: Foram avaliadas as plântulas normais, determinado por ocasião da primeira contagem do teste de germinação, ou seja, no quarto dia após a montagem do teste (BRASIL, 2009).

Emergência de plântulas: conduzido sob condições não controladas de laboratório, utilizando areia lavada e esterilizada em estufa a $200{ }^{\circ} \mathrm{C}$, durante duas horas. As sementes foram semeadas a dois $\mathrm{cm}$ de profundidade em caixas tipo gerbox e o teor de água mantido com irrigações diárias (BRASIL, 2009). Os resultados foram obtidos pelo número de plântulas normais emergidas, determinado por ocasião do sétimo dia após a montagem do experimento.

No final do teste de emergência, foi determinado, com o auxilio de uma régua milimétrica o comprimento das plântulas (raiz até parte aérea) consideradas normais, sendo os resultados expressos em cm plântula ${ }^{-1}$.

Os dados coletados foram submetidos à verificação dos pressupostos da análise de variância, pelos testes de Shapiro-Wilk $(p=0,78)$ e Bartlett $(p>0,10)$. Em seguida, utilizou-se o programa estatístico SISVAR ${ }^{\circledR}$ para avaliação dos resultados, que foram submetidos à análise de regressão. Foram selecionadas as equações de regressão que apresentaram maior coeficiente de determinação $\left(R^{2}\right)$ e com as estimativas dos parâmetros significativas em nível de $5 \%$ de significância pelo teste " $\mathrm{t}$ ".

\section{Resultados e Discussão}

Os resultados do teor de água de sementes de crambe indicaram que, durante a condução do experimento, que as sementes apresentaram valor médio de $10,0 \%$ de umidade. demonstrando que não houve interferência do mesmo nos resultados obtidos nos testes de germinação e vigor. Esse fator é importante para a confiabilidade das demais avaliações e o fornecimento de resultados consistentes. Não permitindo que as análises realizadas sejam afetadas por diferenças na atividade metabólica, velocidade de umedecimento e na intensidade de deterioração das sementes por diferenças iniciais do teor de água (COIMBRA et al., 2009).

Os resultados de germinação se enquadraram numa equação de regressão de comportamento linear (Figura 1). Com o aumento das doses do fertilizante comercial composto por zinco e molibdênio, houve redução na porcentagem de germinação das sementes de crambe. $\mathrm{Na}$ dose máxima $(13,3 \mathrm{~mL})$ do fertilizante, observou-se redução de $67 \%$ em relação ao controle, sendo observados valores de $66 \%$ de germinação. Possivelmente a aplicação do produto tenha causado algum efeito fitotóxico durante o período em que as sementes ficaram expostas aos tratamentos, com comprometimento ao embrião. Dessa forma, doses altas associadas a fontes solúveis levam à toxicidade do nutriente porque as sementes não possuem mecanismo eficiente para evitar a absorção excessiva destes que se encontram em alta concentração.

Figura 1. Germinação de sementes de crambe em resposta ao tratamento com fertilizante à base de zinco e molibdênio.

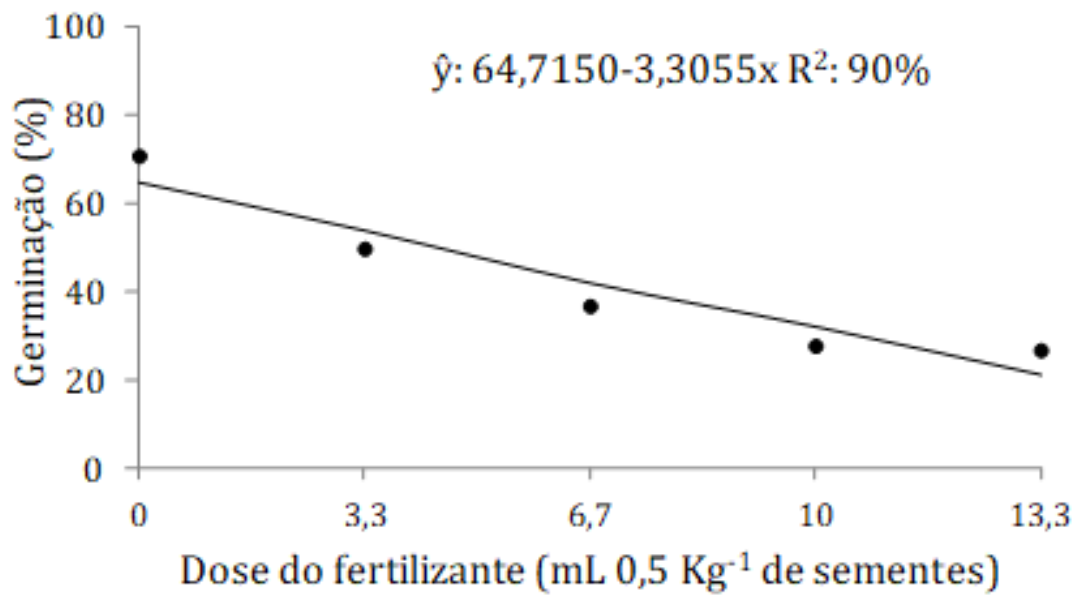

Os resultados deste estudo corroboram com os observados por Pereira et al. (2012), os quais verificaram que doses crescentes de molibdênio, influenciam negativamente a 
germinação de sementes de milho. Segundo os autoresautores, esses resultados podem estar associados a danos causados ao embrião devido às altas concentrações de sal na semente. Entretanto, Ribeiro et al. (1994), testando fontes de zinco e boro na forma de sais e boro da marca comercial Biocrop ${ }^{\circledR}$, aplicadas às sementes de milho na dose recomendada pelo fabricante, não encontraram diferenças entre a testemunha e as sementes tratadas quanto à germinação.

Diversas pesquisas (PESSOA et al., 2000; GONÇALVES JÚNIOR; PESSOA, 2002; LUCHESE et al. 2004) e relatos observado em condições de campo por agricultores, têm demonstrado que a aplicação de micronutrientes via tratamento de sementes, como o molibdênio, próximo à semente, diminui e atrasa a germinação, reduzindo $o$ estande de lavouras e conseqüentemente a produtividade.
Nas Figuras 2, 3 e 4 são apresentados, respectivamente, os resultados de vigor avaliado pelos testes de primeira contagem de germinação, emergência de plântulas, e comprimento de plântulas de crambe em função das doses crescentes de zinco e molibdênio. Os testes de vigor são importantes, pois têm alta correlação com a emergência de plântulas em campo, sendo possível, assim, prever o desempenho destas sementes antes da semeadura (PEREIRA et al., 2012). Nota-se que de maneira similar aos resultados de germinação (Figura 1), o vigor das sementes foi influenciado negativamente pelo acréscimo das doses de zinco e molibdênio, possivelmente ocasionados por danos causados no embrião da semente devido às altas concentrações de sal na semente, conforme explicado por Pereira et al. (2012).

Figura 2. Primeira contagem de germinação de sementes de crambe em resposta ao tratamento com fertilizante à base de zinco e molibdênio.

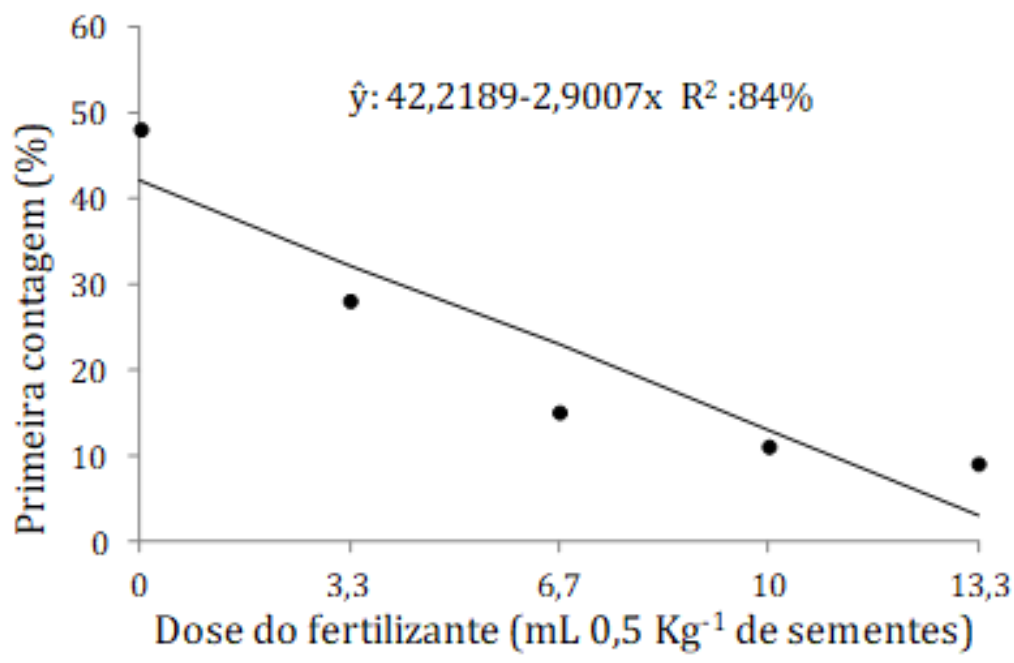

Ribeiro et al. (1996) observaram redução na germinação e no vigor de sementes de milho portadoras de diferentes níveis de qualidade, induzidos através do envelhecimento precoce, e tratadas com diversas doses $(1,25,2,50$ e $5,00 \mathrm{~g}$ $\mathrm{Zn} / \mathrm{kg}$ de sementes) da fonte experimental $\mathrm{Zn}$ MIQL-90a (produto líquido com $21 \% \mathrm{Zn}$ ), com avaliação através do teste da primeira contagem, índice de velocidade de emergência a campo e do tamanho e massa seca de plântulas. Segundo esses autores, esses efeitos negativos foram devidos à interação entre baixa qualidade das sementes e doses elevadas de zinco.

A dose máxima de zinco e molibdênio $(13,3 \mathrm{~mL})$ promoveu uma redução de $18 \%$ na emergência das plântulas de crambe em comparação a testemunha, onde foi verificado aproximadamente $77 \%$ de plântulas emergidas (Figura 3). Possivelmente esse resultado está associado a uma maior sensibilidade das sementes às substâncias constituintes do produto utilizado, com efeito negativo no seu desempenho fisiológico, conforme relatado anteriormente. Neste sentido, Raven et al. (2007), ressaltam que a resposta a um dado regulador não depende somente da sua estrutura química, mas também de como ele é reconhecido pelo tecido alvo. 
Figura 3. Emergência de plântulas de crambe em resposta ao tratamento com fertilizante à base de zinco e molibdênio.

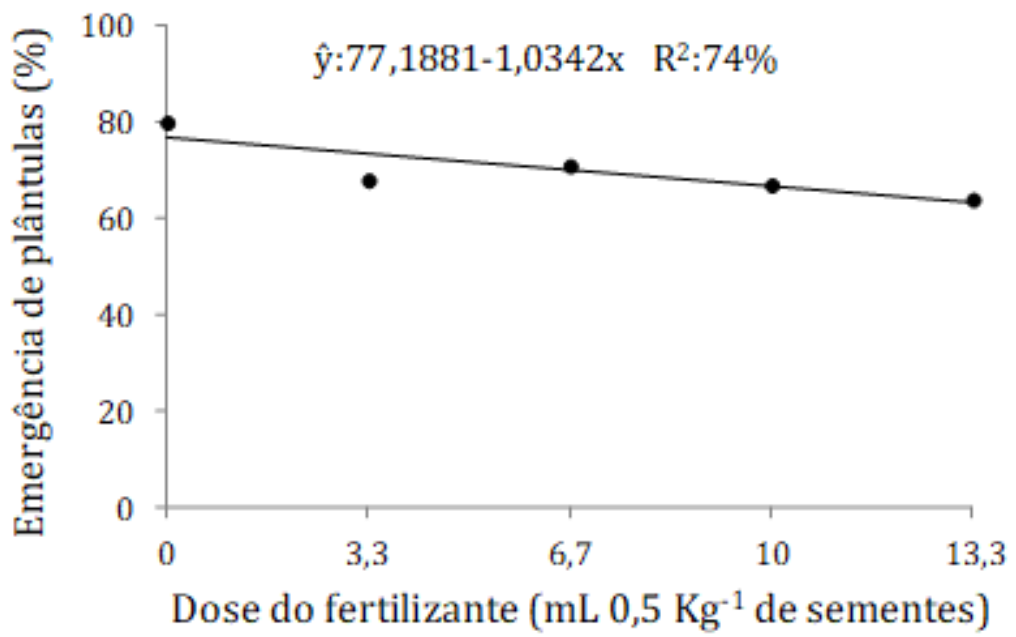

Uma das possíveis explicações para a falta de resposta à aplicação do fertilizante para os parâmetros avaliados pode estar associado à interação entre os micronutrientes presentes no produto, bem como das condições fisiológicas da planta-mãe, da maturação das sementes e base genética da cultivar, sendo necessários mais estudos que avaliem o efeito do produto na cultura do crambe. Adicionalmente, o fato da cultura do crambe apresentar sementes com alto grau de dormência pós-colheita, esse mecanismo pode levar a subestimar a porcentagem de germinação e demais processos envolvidos (ROSOLEM, 1997), conforme verificado nas demais variáveis.

É importante salientar que a quantidade do produto absorvido depende de vários fatores, como o tempo de exposição das sementes ao produto, a quantidade de água presente na solução em aplicações diluídas, bem como a concentração da solução, em aplicação direta. Assim, uma maior ou menor absorção do fertilizante, em função de algum desses fatores, pode comprometer o desempenho fisiológico das sementes.

Porém, para a cultura do Triticum aestivum, a imersão das sementes, por 24 horas, em solução de $0,25 \mathrm{mg} / \mathrm{l}$ de $\mathrm{ZnSO}_{4}$ (sal p.a. com $22,7 \%$ de $\mathrm{Zn})$ promoveu incrementos na porcentagem de germinação de $89 \%$, na massa seca da parte aérea $(11,95 \%)$ e na massa seca de raízes (34,5\%) ( RIBEIRO et al., 1996).

Observa-se que à medida que se aumenta a dose do fertilizante aplicado via sementes, houve redução linear no comprimento das plântulas de crambe (Figura 4).

Figura 4. Comprimento de plântulas oriundas de sementes de crambe em resposta ao tratamento com fertilizante à base de zinco e molibdênio.

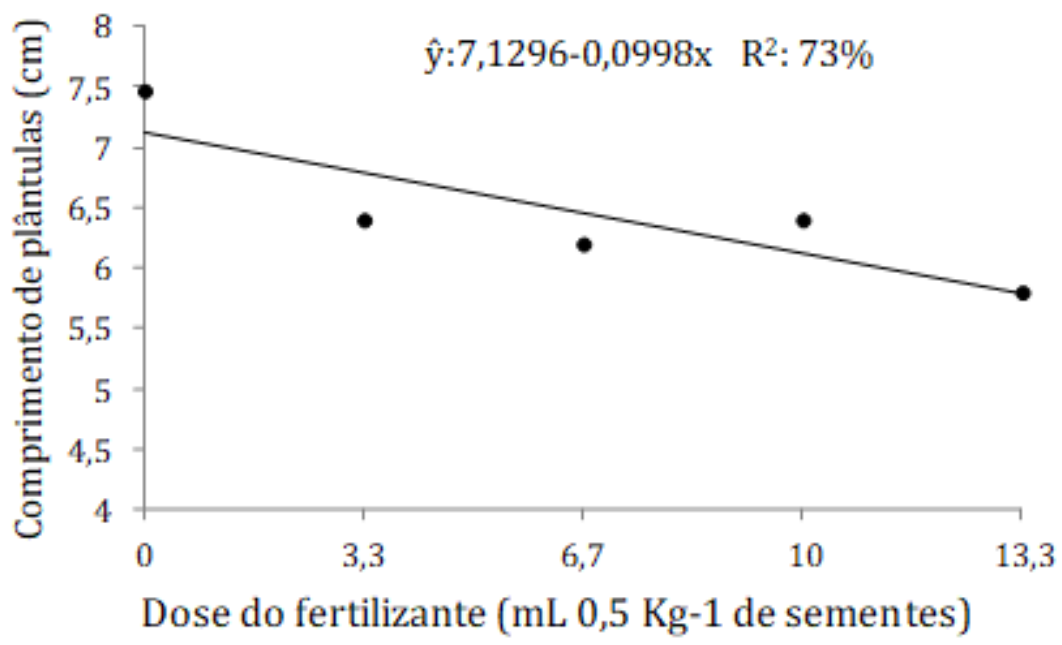


Estudos confirmam melhor qualidade fisiológica das sementes quando são produzidas por plantas submetidas à fertilização, ou quando as próprias sementes são fertilizadas (ABDALLA et al., 2008). Segundo Favarin et al. (2000), apesar dos micronutrientes serem exigidos em pequenas quantidades são elementos essenciais para o desenvolvimento das plantas devido às funções que exercem no metabolismo das mesmas atuando como catalisadores de diversos processos fisiológicos e hormonais. O emprego de novas tecnologias no setor de sementes, como a utilização de aditivos no tratamento de sementes, poderia trazer benefícios, aumentando a sua germinação e o vigor e, consequentemente, a qualidade das plântulas no estabelecimento de novas áreas de produção. A principal característica do tratamento de sementes é a aplicação de pequenas doses desses produtos com alta precisão, contribuindo para a redução de custos e produtos químicos lançados ao meio ambiente (ALBUQUERQUE et al., 2009).

Entretanto, são necessários mais estudos sobre o efeito de produtos contendo micronutrientes sobre $\mathrm{o}$ desempenho de sementes de crambe.

\section{Conclusões}

Com o aumento das doses do fertilizante comercial composto por zinco e molibdênio, houve redução na qualidade fisiológica de sementes de crambe.

\section{Referências}

ABDALLA, S. R. S.; PROCHNOW, L. I.; FANCELLI, A. L. Simpósio discute como utilizar insumos e recursos para otimizar a produtividade do milho. Piracicaba: International Plant Nutrition Institute - Brasil, 2008. (Informações Agronômicas, 122).

ALBUQUERQUE, K.A.D.; SILVA, P.A.; OLIVEIRA, J.A.; FILHO, J.L.S.C.; BOTELHO, J.E. Desenvolvimento de mudas de alface a partir de sementes armazenadas e enriquecidas com micronutrientes e reguladores de crescimento. Bioscience Journal, v. 25, p.56-65, 2009.

BARBOSA, R. M.; SILVA, C. B. DA; MEDEIROS, M. A. DE; CENTURION, M. A. P. DA C.; VIEIRA, R. D. Condutividade elétrica em função do teor de água inicial de sementes de amendoim. Revista Ciência Rural, v.42, p.45-51, 2012. https://doi.org/10.1590/S010384782012000100008
BRASIL. Ministério da Agricultura, Pecuária e Abastecimento. Regras para análise de sementes. Brasília: SNAD/DNDV/CLAV, 2009, $395 p$.

COIMBRA, R.A.; MARTINS, C.C.; TOMAZ, C.A.; NAKAGAWA, J. Testes de vigor utilizados na avaliação da qualidade fisiológica de lotes de sementes de milho-doce (sh2). Ciência Rural, v.39, n.9, p.2402-2408, 2009. https://doi.org/10.1590/S0103$\underline{84782009000900004}$

COLODETTI, T. V.; MARTINS, L. D.; RODRIGUES, W. N.; BRINATE, S. V. B.; TOMAZ, M. A. Crambe: Aspectos Gerais da Produção Agrícola. Revista Enciclopédia Biosfera, v. 8, p. 258-269, 2012.

EPSTEIN, E.; BLOOM, A. J. Mineral nutrition of plants: principles and perspectives. 2. ed. Sunderland: Sinauer Associates, 2004. 400p.

FAVARIN, J.L.; MARINI, J.P. Importância dos micronutrientes para a produção de grãos. In: Sociedade Nacional da Agricultura, 2000.

FERREIRA, L.A.; OLIVEIRA, J.A.; VON PINHO, É.V.R.; QUEIROZ, D.L. 2007. Bioestimulante e fertilizante associados ao tratamento de sementes de milho. Revista Brasileira de Sementes, v.29, p.80-89, 2007. https://doi.org/10.1590/S0101$\underline{31222007000200011}$

GONÇALVES, J.R.A.C.; PESSOA, A.C.S. Fitodisponibilidade de cádmio, chumbo e cromo, em soja cultivada em Argissolo Vermelho eutroférrico a partir de adubos comerciais. Revista Scientia Agraria, v.3, p.19-23, 2002. https://doi.org/10.5380/rsa.v3i1.1026

LUCHESE, A. V.; GONALVES JUNIOR, A. C.; LUCHESE, E. B.; BRACCINI, M. C. L. Emergência e absorção de cobre por plantas de milho (Zea mays) em resposta ao tratamento de sementes com cobre. Revista Ciência Rural, v.34, p.19491952, 2004. https://doi.org/10.1590/S0103$\underline{84782004000600044}$

MENDEL, R. R.; SCHWARZ, G. Molybdoenzymes and molybdenum cofactor in plants. Critical Review in Plant Science, v.18, p.33-69, 1999. 
MERLOT, S.; GIRAUDAT, J. Genetic analysis of abscisic acid signal transduction. Plant Physiol, v.114, p.751-757, 1997. https://doi.org/10.1104/pp.114.3.751

PEREIRA, F.R.S.; BRACHTVOGEL, E. L.; SIMÉRIO, C. S. C.; BICULDO, S.J.; MACHADO, C.G.; PEREIRA, J.C. Qualidade fisiológica de sementes de milho tratadas com molibdênio. Revista brasileira de Sementes, v.34, n.3, p. 450-456, 2012. https://doi.org/10.1590/s0101-

$\underline{31222012000300012}$

PITOL, C.; BROCHI, D. L.; ROSCOE, R. Tecnologia e produção: crambe 2010. Maracajú: FUNDAÇÃO MS, 2010b. p. 60.

PESSOA, A. C. S.; LUCHESE, E. B.; LUCHESE, A. V. Germinação e desenvolvimento inicial de plantas de milho, em resposta ao tratamento de sementes com boro. Revista Brasileira de Ciência do Solo, v.24, n.4, p.939-945, 2000. https://doi.org/10.1590/S0100-

$\underline{06832000000400025}$

RAVEN, P.H. Biologia vegetal. 7. ed. Rio de Janeiro: Guanabara Koogan, 2007. 830p.

RIBEIRO, N.D.; SANTOS, O.S.; MENEZES, N.L. Tratamento de sementes de milho com fontes de zinco e boro. Revista Brasileira de Sementes, v.16, p.116-120, 1994. https://doi.org/10.17801/0101-

3122/rbs.v16n2p116-120

RIBEIRO, N.D.; SANTOS, O.S. Aproveitamento do zinco aplicado na semente na nutrição da planta. Ciência Rural, v.26, p.159-165, 1996. https://doi.org/10.1590/S0103-

84781996000100030

ROSOLEM, C.A. Stimulate em tratamento de sementes de feijão. Botucatu: UNESP, 1997. 5p. (Relatório Técnico)

SOUZA, A. D. V.; FÁVARO, S. P., ÍTAVO, L. C.; ROSCOE, R. Caracterização química de sementes e tortas de pinhão-manso, nabo-forrageiro e crambe. Pesquisa Agropecuaria Brasileira, v.44, p.1328-1335, 2009. https://doi.org/10.1590/S0100$\underline{\text { 204X2009001000017 }}$ 